\title{
X-ray Emission Spectroscopy as an In Situ Diagnostic Tool for X- ray Crystallography of Metalloproteins Using an X-ray Free Electron Laser
}

\author{
Thomas Fransson ${ }^{a, \S, \#, ~ R u c h i r a ~ C h a t t e r j e e ~}{ }^{\mathrm{b}, \#}$, Franklin D. Fuller ${ }^{\mathrm{c}}$, Sheraz Gul $^{\mathrm{b}}$, Clemens \\ Weninger $^{c}$, Dimosthenis Sokaras ${ }^{d}$, Thomas Kroll ${ }^{d}$, Roberto Alonso-Mori ${ }^{c}$, Uwe \\ Bergmann ${ }^{a},{ }^{*}$, Jan Kern ${ }^{b},{ }^{,}$, Vittal K. Yachandra ${ }^{b,}$, and Junko Yano ${ }^{b,}$ \\ aStanford PULSE Institute, SLAC National Accelerator Laboratory, Menlo Park, California, USA \\ bMolecular Biophysics and Integrated Bioimaging Division, Lawrence Berkeley National \\ Laboratory, Berkeley, California, USA \\ 'LCLS, SLAC National Accelerator Laboratory, Menlo Park, California, USA \\ dSSRL, SLAC National Accelerator Laboratory, Menlo Park, California, USA
}

\begin{abstract}
Serial femtosecond crystallography (SFX) using the ultra-short X-ray pulses from a X-ray freeelectron laser (XFEL) provides a new way of collecting structural data at room temperature that allows for following the reaction in real time after initiation. XFEL experiments are conducted in a shot-by-shot mode as the sample is destroyed and replenished after each X-ray pulse - monitoring and controlling the data quality by using in situ diagnostic tools is thus critical. To study metalloenzymes, we developed the use of simultaneous collection of X-ray diffraction of crystals along with X-ray emission spectroscopy (XES) data that is used as a diagnostic tool for crystallography, by monitoring the chemical state of the metal catalytic center. We have optimized data analysis methods and sample delivery techniques for fast and active feedback to ensure the quality of each batch of samples and the turnover of the catalytic reaction caused by reaction triggering methods. Here, we describe this active in situ feedback system using Photosystem II as an example that catalyzes the oxidation of $\mathrm{H}_{2} \mathrm{O}$ to $\mathrm{O}_{2}$ at the $\mathrm{Mn}_{4} \mathrm{CaO}_{5}$ active site. We used the first
\end{abstract}

\footnotetext{
*Corresponding Authors: bergmann@slac.stanford.edu,, jfkern@1bl.gov, vkyachandra@lbl.gov, jyano@lbl.gov.

\$Present address: Interdisciplinary Center for Scientific Computing, University of Heidelberg, Im Neuenheimer Feld 205, 69120 Heidelberg, Germany

\# $_{\text {These two authors contributed equally }}$

Supporting Information

Supporting information feature details on sample preparation, delivery and off-line characterization, XES spectroscopy set-up, energy calibration, charge-sharing reconstruction algorithm, spectroscopic hit finder and background subtraction, and choice of adopted energy interval for first moment calculation.

ORCID

Thomas Fransson: 0000-0002-3770-9780

Sheraz Gul: 0000-0001-8920-8737

Dimosthenis Sokaras: 0000-0001-8117-1933

Roberto Alonso-Mori: 0000-0002-5357-0934

Uwe Bergmann: 0000-0001-5639-166X

Jan Kern: 0000-0002-7272-1603

Junko Yano: 0000-0001-6308-9071
} 
moments of the $\mathrm{Mn} \mathrm{K} \beta_{1,3}$ emission spectra, highly sensitive to the oxidation state of $\mathrm{Mn}$, as the primary diagnostics. This approach is applicable to different metalloproteins to determine the integrity of samples and follow changes in the chemical states of the reaction that can be initiated by light or activated by substrates, and offers a metric for determining the diffraction images that are used for the final datasets.

\section{Introduction}

The structure of metalloenzymes has been studied extensively using X-ray crystallography at synchrotron radiation sources. As the data are typically collected at cryogenic temperatures, these synchrotron based X-ray studies are often limited to resting states or stable intermediates that can be cryo-trapped. While cryo-cooling the crystals is required in order to minimize X-ray-induced radiation damage, there is a strong interest in studying systems under functional conditions during enzymatic reactions. X-ray free-electron lasers (XFELs) have opened the possibility for such studies as their femtosecond ultra-bright X-ray pulses can outrun X-ray-induced sample damage. ${ }^{1-8}$ In this approach, known as serial femtosecond crystallography (SFX), the micron-size crystals are replaced after each X-ray pulse and the three dimensional protein structure is obtained by combining the diffraction data of thousands of randomly oriented crystals. SFX is also used to follow changes in the structure of the protein as the enzymatic reaction proceeds, which can be initiated by light or activation by a substrate. We have used SFX, simultaneously with XES to study the lightinduced oxidation of water to $\mathrm{O}_{2}$ by the $\mathrm{Mn}_{4} \mathrm{CaO}_{5}$ cluster in Photosystem II (PS II). Similar pump-probe studies of metalloenzymes, initiated by light as in PS II, or substrates including gases have been studied using the combined SFX/XES method.

One of the challenges of the SFX approach is sample heterogeneity, which is an inevitable consequence of how the experiment is carried out. To collect a complete dataset, one needs to average the diffraction data from several thousand diffraction images, and each image is from a different crystal, that differs in size, quality, and is likely from different batches of preparation. This implies that quality control of the sample is critical, more so than in traditional synchrotron crystallography (where only one or a few crystals need to be checked), in order to avoid the inclusion of data from damaged or non-functional crystals. Since changes in the electron density between the different states of the protein can be subtle, any erroneous data can lead to serious misinterpretations.

There are many proteins that are stable and can be prepared ahead of time and shipped frozen to X-ray sources. However, micron-size crystals of some metalloproteins for room temperature XFEL experiments can be especially sensitive to temperature, light, oxygen, and environmental conditions. Crystals from such proteins are preferably made on-site so that the quality is not compromised with storage time for room temperature measurements. The crystals can start degrading leading to a decrease in the activity, due to small changes in conditions like temperature, hydration during sample handling, and the time interval from when the crystals are prepared and the data is collected, especially if left at room temperature for several hours. Therefore, in situ monitoring of the sample quality becomes critically important for XFEL experiments, in addition to ex situ sample characterization in 
the lab. For pump-probe experiments, where the generation of intermediate states, triggered by light, substrates, or by other methods, is studied, it is valuable to have an independent in situ method for confirming the generation of such intermediates. With the direct active feedback about crystal quality at the XFELs, the crystals can be optimized on-site to improve the quality of the crystallography data. This flexibility for optimizing the quality of protein crystals on-site is critical for successful crystallography data collection for many proteins.

Recently, we introduced the approach of XFEL based simultaneous X-ray diffraction (XRD) (which in this context is equivalent to SFX) and X-ray emission spectroscopy (XES) ${ }^{9}$ for metalloenzymes, to probe the interplay between the chemical state of the metals in the catalytic site and the overall protein structure during enzymatic reactions. ${ }^{10-13}$ This method also allows us to confirm the integrity of the sample and the catalytic turnover, by providing an in situ diagnostic tool for determining the oxidation state of the metal in the active sites. The use of XES is well suited because the excitation energy can be the same as for XRD, therefore enabling simultaneous data collection. With XES, the highest occupied molecular orbital levels are probed through the decay of core-ionized states, giving information on the electronic structure, charge/spin density, and ligands. ${ }^{14-17}$ Among the several emission lines, both $\mathrm{Ka}(2 \mathrm{p}-1 \mathrm{~s})$ and $\mathrm{K} \beta_{1,3}(3 \mathrm{p}-1 \mathrm{~s})$ XES can serve as a diagnostic tool for crystallography. $\mathrm{K} \beta_{1,3}$ is more sensitive to the oxidation and spin state (given by the number of unpaired $3 \mathrm{~d}$ electrons) than $\mathrm{Ka} \mathrm{XES}$, as the $3 \mathrm{p}-3 \mathrm{~d}$ interactions are stronger than the $2 \mathrm{p}-3 \mathrm{~d}$ interactions. XES can also be used for monitoring the primary electronic damage, which can occur with high density X-ray dose experiments at XFELs due to, for e.g., multiphoton absorption events. $9,18,19$ While both $\mathrm{Ka}$ or $\mathrm{K} \beta$ can be used for the purpose of the experiments, we describe here the use of $\mathrm{K} \beta$ energy shift measured by the 1st moment, compared to Ka where one needs to monitor changes in the width of the peak which is more subtle and harder to detect.

The XRD/XES data collection setup, which can be used with either a liquid microjet injector $^{20,21}$ or the more recent Drop-on-Tape (DOT) ${ }^{13}$ method is shown in Fig. 1. The XES spectrometer is positioned orthogonal to the beam along the XFEL polarization direction to minimize the background from elastic scattering. ${ }^{17}$ Such a multimodal experiment can be inefficient if the microcrystals are too small leading to an insufficient XES signal, as it is the case with the liquid microjet sample delivery systems. The DOT method overcomes this problem by ensuring a high measurement/probing efficiency and the use of larger crystal size (>20 micrometer crystals in droplets), making XES a powerful in situ diagnostic tool for XRD. Using this approach, we monitored the intactness of the metal site in several metalloenzyme crystals during XRD. We demonstrated successful $\mathrm{O}_{2}$ activation of $\mathrm{Mn} / \mathrm{Fe}$ Ribonucleotide Reductase (RNR) upon in situ mixing of the sample droplets with $\mathrm{O}_{2}$ gas, including the observation of a high valent intermediate state in the activation cycle of RNR, as well as efficient light activation of Photosystem II (PS II) samples. ${ }^{13}$

In this study, we describe in detail the use of XES as a diagnostic tool to get active online feedback for SFX of metalloenzymes. We focus on the significant improvements that have enabled the use of XES data from crystals quantitatively to determine both the sample quality and changes in chemical states induced in time resolved experiments. Here, we 
illustrate this general method by its application to the study of PS II, a membrane protein complex that catalyzes the oxidation of water to dioxygen at the $\mathrm{Mn}_{4} \mathrm{O}_{5} \mathrm{Ca}$ cluster using multiple laser flashes. ${ }^{22,} 23$ This light activated reaction progresses from the dark stable $\mathrm{S}_{1}$ state through four intermediate $S\left(S_{2}-S_{3}-S_{4}-S_{0}\right)$ states (see Fig. $S 1$ in Supplementary Information) where $S_{3}$ is the most oxidized, and $S_{0}$ is the most reduced state. Monitoring the Mn oxidation state with $\mathrm{K} \beta_{1,3}$ XES provides information about, i) the integrity of samples, and ii) the degree of catalytic turnover by photo-excitations.

\section{Materials and Methods}

XES on PS II microcrystals was measured using the Macromolecular Femtosecond Crystallography (MFX) ${ }^{24}$ instrument at LCLS. ${ }^{25}$ Here, we present data collected during two separate experimental runs (referred to as experiment 1 and experiment 2). During the experiment, the sample is measured in $1 \mathrm{~mL}$ batches introduced via a syringe at a flow rate of $3 \mu \mathrm{L} / \mathrm{min}$. Each $1 \mathrm{~mL}$ sample batch is from a separate on-site crystallization set-up and is referred to as a (sample) 'batch' in this manuscript. The details of the sample preparation, experimental set-up, and data analysis, as well as other relevant details, are in the Supporting Information. ${ }^{13,26}$ The set-up used a von Hamos spectrometer ${ }^{9,27}$ to measure the entire $\mathrm{K} \beta_{1,3}$ emission spectrum on a shot-by-shot basis. ${ }^{9,16,17,27}$ The signal was collected on an ePix 100 detector ${ }^{28}$ with a pixel size of $50 \mu \mathrm{m}$. This leads to spreading of the charge cloud generated by a single X-ray photon over multiple pixels on the detector, also referred to as 'charge-sharing' for single photon events. ${ }^{29} \mathrm{~A}$ signal reconstruction algorithm was used to correct for this phenomenon and was critical to separate emission and scattering signals (Fig. S2). Further, the data was pedestal and gain corrected to account for differences in noise and gain of the detector pixels. The spectrometer geometry was calibrated with $\mathrm{MnCl}_{2}$ as reference. ${ }^{9}$ In order to discard emission images with low or no signal (i.e. we either hit droplets without crystals or miss the droplets entirely) a spectroscopic hit finder was used (Fig. S3), where the number of emission photon counts inside and outside the Region of Interest (ROI) was compared (Figs. 2 and S4).

For studies of very dilute systems with low signal level, an analysis of the full spectra or difference spectra is difficult. In such cases, the first moment is found to be more suitable for determining small shifts, as statistics from the entire spectrum are used. ${ }^{30,} 31$ The first moment is calculated as

$$
1^{\mathrm{st}} \text { Moment }=\sum_{i}\left(E_{i} \times I_{i}\right) / \sum_{i} I_{i}
$$

where $E_{i}$ and $I_{i}$ are the X-ray energy and emission intensity of data point $i$, respectively. For $\mathrm{Mn}$ this is calculated over the energy range $6485-6495 \mathrm{eV}^{30-35}$ of splined spectra to ensure equally spaced energy points. The energy per pixel was originally spread over $0.026-0.038$ $\mathrm{eV}$, and was splined to a resolution of $0.010 \mathrm{eV}$ using a cubic spline algorithm. Other energy intervals for first moment calculations were tested to ensure the results are not affected/ biased by the choice of the interval, with results illustrated in Fig. S5. The first moment measures the 'center of mass' of the spectrum and gives an estimate of the oxidation state by probing primarily peak shifts due to different effective numbers of metal $3 \mathrm{~d}$ electrons. ${ }^{15}$, 30 


\section{Results}

\section{Monitoring Sample Hits}

The sample hit rates were measured by a spectroscopic hit finder as well as by the indexing rates from crystallography. The resulting hit/indexing rates are illustrated in Fig. 2 (right).

The spectroscopic hit finder measures the number of emission photons inside and outside the ROI. A shot is considered to be a hit, if the number of emission photons in the ROI is greater or equal to a threshold value (Threshold I), and if the ratio of photons per unit area inside the ROI and outside the ROI is greater or equal to a second threshold value (Threshold II). The selection of ROI and neighboring slices used for background subtraction and second hit finder selection criteria are illustrated in Fig. 2 (left), as employed for the analysis of data collected during experiment 1 . Details on the spectroscopic hit finder are provided in the Supporting Information (Fig. S3 and related discussion), illustrating the first moment trends of the XES K $\beta_{1,3}$ peak for different choices of thresholds. The results reported for the rest of this study are obtained using are for values of 3 for Threshold I and 2 for Threshold II, chosen based on an analysis of first moment variance minimization. Importantly, it is illustrated that the relative trends are preserved with different parameters as well as including all emission images with the absolute energies varying primarily due to background effects. The improvement in signal-to-noise ratio is further illustrated in Fig. S4 (bottom), where it is shown that first moment error estimates decrease when using a hit finder, despite the lower number of included XES images.

As shown in Fig. 2, spectroscopy and crystallography data give similar trends of hit/indexing rates, with an offset, as crystallography has a stronger dependence on the microcrystal quality. We note that $91 \%$ of the indexed XFEL shots are also considered as XES hits, while the remaining $9 \%$ of crystal hits exhibit a high noise level and thus do not fulfill Threshold II (the ratio of hits per unit area in the ROI versus outside the ROI) of our spectroscopic hit finder. By comparison, only about half the XES hits can also be indexed. The fluctuations in hit/indexing rates are related to differences in crystal concentration and/or size from batch to batch. The analysis of individual batches is important (as discussed in later sections) to detect subtle variations in sample quality.

\section{X-ray Emission Spectroscopy on Microcrystals of Metalloproteins}

The $\mathrm{K} \beta_{1,3}$ XES of two states of PS II is shown in Fig. 3. Illustrated is the raw and smoothed spectra of the dark-adapted, 0 -flash (0F) and two-flash (2F) samples, as well as the difference spectra between these two states. The spectra are obtained by integrating along the spatial axis in the ROI, as illustrated in Fig. 2 (left), accounting for background level and the gap (dark line) between the detector panels. The difference in photon counts between the two spectra can be seen by observing the larger fluctuations in the raw $0 \mathrm{~F}$ spectrum as compared to the raw $2 \mathrm{~F}$ spectrum. Fig. 3 shows that there is no change in the spectral features between the raw and smoothed spectra. The $0 \mathrm{~F}$ state is dominantly in the $\mathrm{S}_{1}$ state, in which the formal oxidation state of the four Mn is (III,III,IV,IV). Upon each flash, one $\mathrm{Mn}$ is oxidized formally from III to IV, from $0 \mathrm{~F}\left(\mathrm{~S}_{1}\right.$-state) to $1 \mathrm{~F}\left(\mathrm{~S}_{2}\right)$ state, and then to the doublyilluminated $2 \mathrm{~F}\left(\mathrm{~S}_{3}\right)$ state with $\mathrm{Mn}_{4}(\mathrm{IV}, \mathrm{IV}, \mathrm{IV}, \mathrm{IV})$. It eventually goes back to the most reduced $\mathrm{S}_{0}$ state with $\mathrm{Mn}_{4}(\mathrm{III}, \mathrm{III}, \mathrm{III}, \mathrm{IV})$ upon subsequent photon absorption $(3 \mathrm{~F}) .{ }^{22,} 36$ There is a 
change of the local charge and spin distributions of $\mathrm{Mn}$ as well as its geometry in each of the illuminated states. As expected, we observe that the spectrum from the most oxidized $2 \mathrm{~F}$ state is shifted to a lower energy compared to the $0 \mathrm{~F}$ state spectrum, as clearly evident in the difference spectra of the $0 \mathrm{~F}$ and $2 \mathrm{~F}$ states (Fig. 3 (bottom)).

For weak XES signals from dilute samples, the first moment of the XES peak can be a more reliable measure than the peak position, as the use of integrated photon counts makes it less sensitive to noise, while retaining sensitivity to changes of spectral features in the energy region considered. This is the case also for other measures that account for integrated signal rather than individual feature positions, such as the Integrated Absolute Difference (IAD), which has also been shown to exhibit similar properties as the first moment. ${ }^{31}, 32,37,38$ Using the first moment, we can track sub-pixel changes in the 'center-of-mass' position of the features. The first moment of Mn XES spectrum decreases with increase in the oxidation state, as a result of the red-shift of the $\mathrm{K} \beta_{1,3}$ peak due to $3 \mathrm{p} 3 \mathrm{~d}$ exchange interactions, and $\mathrm{K} \beta_{1,3} \mathrm{XES}$ has been shown to be more sensitive to oxidation state than changes in the ligand environment. ${ }^{34}$ We observe a shift of approximately $0.1 \mathrm{eV}$ in the first moments of measured OF to $2 \mathrm{~F}$ data (see sections below, as well as Figs. S3 and S5) that is in line with previous results. ${ }^{30}$ We note that first moments have been shown to exhibit linear dependence on oxidation state, see for example 1s $2 p$ resonant inelastic X-ray scattering (RIXS) of Mn oxides, ${ }^{39} \mathrm{~K} \beta_{1,3}$ XES of Mn complexes, ${ }^{16,30,33,34}$ and $\mathrm{K} \beta_{1,3}$ XES of PS II. ${ }^{35}$ However, for PS II, RIXS experiments have demonstrated that the electron density is delocalized throughout the cluster compared to model complexes. ${ }^{22,40}$ This illustrates the need to go beyond the simple representation of formal oxidation states to explain the differences in first moments observed between model complexes and PS II, but this discussion is beyond the scope of this study.

In summary, we observe similar absolute and difference XES spectra of the 0F and 2F states in our two experimental runs compared to PS II solution and crystal samples previously measured at synchrotron or XFEL sources. ${ }^{10-13,17}$

\section{Data Collection Time and Required Signal to Noise}

Fig. 4 shows the standard deviation of the first moment, as well as the progression of the first moment for two flash states ( $0 \mathrm{~F}$ and $2 \mathrm{~F}$ ), as a function of the number of detected $\mathrm{K} \beta_{1,3}$ emission photons. This allows us to determine the collection time required for XES to give a verdict on the oxidation state progression of a sample batch, as well as to obtain statistically reliable first moment shifts.

First moment error estimates were obtained by randomly dividing all spectra in a data set into two groups and calculating the first moments for each group, and repeating the procedure 1,000 times and calculating the standard distribution of resulting sets. Fig. 4 (left) illustrates the final first moment standard deviation for all measured flash states as well as a power fitted trend line. These standard deviations are calculated for all individual flash conditions measured for experiments 1 and 2. It is clear that the error is primarily due to photon noise and not from any other non-random source, with a relation between the photon count and standard deviation very close to a square-root dependence (0.485). 
In Fig. 4 (right) we illustrate the convergence of the $0 \mathrm{~F}$ and $2 \mathrm{~F}$ measurements for the first experiment, including also the estimated error at any count position as obtained from the fitting in Fig. 4 (left). In order to get sufficient statistics to estimate whether a batch progress properly (e.g. difference between $0 \mathrm{~F}$ and $2 \mathrm{~F}$ first moments), we require approximately 10,000 photon counts (yielding error estimates of $0.026 \mathrm{eV}$ ). In order to get significant changes between $0 \mathrm{~F}$ and $2 \mathrm{~F}$ for a study of batch progression approximately 10,000 counts is likely sufficient (yielding error estimates of $0.026 \mathrm{eV}$ ). Note that counts are after background subtractions. With about 8 emission photon counts per shot and a hit rate of $40 \%$, this would be approximately 1,200 sample hits, which requires circa 3,000 total XFEL pulses. These photon count and hit rate values are conservative estimates from experiment 1 , where the hit rate was typically $>40 \%$ (see Fig. 2 ) and the average number of photons detected for shots characterized as hits typically exceeding 8 (7.9/8.8 for the $0 \mathrm{~F} / 2 \mathrm{~F}$ data reported in Fig. 3). At $10 \mathrm{~Hz}$ repetition rate this would amount to 5 minutes of data collection per flash state for PS II samples. With the present data reduction algorithm, we obtain first moment values on a close to real time basis, with data available for analysis typically within a few minutes after data collection. This allows very rapid validation of data quality on-site. This method is applicable to metalloenzymes in general.

By comparison, if a final standard deviation of $0.005 \mathrm{eV}$ is desired per flash state, approximately 200,000 counts per state are required. With parameters given above, this requires 100 minutes of collection time per flash state. In comparison, a collection time of about 250 minutes is required (assuming $20 \%$ indexing rate) to obtain a diffraction data set containing $\sim 30,000$ indexed diffraction images, which is a data set size that we have commonly used in the SFX experiment.

\section{Monitoring Sample Quality and Advancement Through the Catalytic Cycle}

The sample integrity of the different batches, as well as the integrity of the flash scheme can be ensured by studying a combination of hit rates, first moments, and first moment progression of individual batches. A shift of the first moment of $0 \mathrm{~F}$ to higher energy can be caused by release of $\mathrm{Mn}$ (II) from the OEC during on-site sample handling. Therefore the $0 \mathrm{~F}$ first moment can be used as a highly sensitive probe to detect even subtle changes in sample quality. Additionally, the progression trend of the first moment can be used to ensure the integrity of the laser illumination, which may be compromised due to non-optimum alignment or insufficient laser power.

In order to check the sample quality on a batch-by-batch basis, we first calculated the average first moment of an individual batch. This number was shifted according to different flash conditions (e.g. the time spent collecting data in different flash states) to obtain the 'estimated $0 \mathrm{~F}^{\prime}\left(\mathrm{OF}_{\text {est }}\right)$ first moment of an individual batch, which can be directly compared. In Fig. 5 we illustrate this $0 \mathrm{~F}_{\text {est }}$ first moment of individual sample batches to estimate $\mathrm{Mn}$ (II) content. The photon counts for the individual batches shown falls between 72,000 and 141,000 , with a single batch with a higher photon count of approximately 250,000. From the standard deviation fit in Fig. 4 this corresponds to errors of approximately 0.007-0.010 eV, with the larger batch at around $0.006 \mathrm{eV}$. Thus the $0 \mathrm{~F}_{\text {est }}$ first moment of XES measurements is sensitive to very small changes and we could detect as small as $1-2 \% \mathrm{Mn}$ (II) content in 
our samples. We note that the first four batches all cluster within a small energy interval, with $0 \% \mathrm{Mn}$ (II) (dashed black line). However, for the last four batches the $0 \mathrm{~F}_{\text {est }}$ first moment is higher (particularly for batches 7 and 8).

The amount of $\mathrm{Mn}$ (II) in a sample can also be estimated using EPR. Aliquots of three of the sample batches in Fig. $5(2,7,8)$ were stored and used for subsequent determination of the $\mathrm{Mn}(\mathrm{II})$ content by EPR (Fig. S6). The percentages of Mn(II) derived from these EPR measurements are represented as red squares in Fig. 5, which can be compared to the XES results. As can be seen, the EPR trends are similar to XES, i.e., batch 2 shows no significant $\mathrm{Mn}$ (II) signal while batches 7 and 8 do have significant $\mathrm{Mn}$ (II) (>8\%).

The differences in Mn(II) estimates between EPR and XES can partially be attributed to the fact that they were measured at different times, and also the methods have different errors. For EPR, performed later at cryogenic temperatures an error of $<10 \%$ was observed for crystal suspension with low Mn concentrations. For XES there is an error of 1-2\% due to photon statistics.

As such, while $0 \mathrm{~F}_{\text {est }}$ first moment is indicative of $\mathrm{Mn}$ (II) content, this is not sufficient to ensure proper advancement through the catalytic cycle by photo-illumination. This can be ensured by additionally computing first moments for different flash states. A trend of flat first moment progression of the flash states (i.e. no oxidation in the $0 \mathrm{~F}-2 \mathrm{~F}$ or reduction in the $2 \mathrm{~F}-3 \mathrm{~F}$ ) is indicative of problems with the laser illumination or insufficient acceptor (quinone) present in the samples. Therefore, we use a combination of the $0 \mathrm{~F}_{\text {est }}$ first moment and the progression for different flash states to determine the quality of a batch. We assigned each batch into one of three categories: (a) "good", the sample shows expected progression in first moments and no free $\mathrm{Mn}$ (II); (b) "intermediate", the sample shows progression in first moments with $<5 \%$ of $\mathrm{Mn}$ (II); (c) "bad", the sample shows a flat progression in first moments indicating no change in the S states or $>5 \%$ of Mn(II). Thus, we use XES as an effective in situ tool for determining the sample quality and the integrity of the experimental setup.

Fig. 6 shows the comparison of first moment trends of batches 5-7 from Fig. 5 with the good batches (category a) labeled as merged. The individual first moments for batches 1-4 showed no indication of $\mathrm{Mn}$ (II) and progressed as expected (data not shown), and therefore include in the merged data set. Batch 5 has a low $\mathrm{Mn}(\mathrm{II})$ content $(\sim 4 \%)$ indicated from the $0 \mathrm{~F}_{\text {est }}$ first moment (Fig. 5), but the first moment progression in Fig. 6 is inconsistent with the good batches. We traced this lack of progression to incorrect laser power/alignment that produces flat features, or insufficient acceptor presence that will show a shift between $0 \mathrm{~F}$ to $1 \mathrm{~F}$, but no shifts between $1 \mathrm{~F}$ to $2 \mathrm{~F}$ and $2 \mathrm{~F}$ to $3 \mathrm{~F}$. Batch 5 is categorized in the former case, and this batch was not used for the crystallography data analysis. On the other hand, batch 6 shows the expected progression of the first moments in the flash states, but exhibited $\sim 3 \% \mathrm{Mn}$ (II) (Fig. 5). This could happen if there is free Mn(II) outside of the OEC. As this does not affect the activity of the OEC and non-specific Mn(II) does not contribute to the density of the OEC, this batch was included in the XRD data analysis. In case of batch 7, it has an absolute shift in energy due to free $\mathrm{Mn}$ (II) (>10\% Mn(II)), and also does not show an expected 
progression in the first moment between $1 \mathrm{~F}$ to $3 \mathrm{~F}$. In general, such batches with $>5 \% \mathrm{Mn}$ (II) were not included in XRD data analysis.

\section{Conclusions}

We report X-ray emission measurements on microcrystals under functional conditions using an X-ray free-electron laser. It is demonstrated that XES provides a reliable diagnostics tool for SFX measurements, enabling in situ measurements on identifying sample integrity and PS II photocatalytic turn-over rates. From this we have identified sample batches where there was Mn(II) content, as well as incorrectly aligned laser flashing schemes. Estimates of $\mathrm{Mn}(\mathrm{II})$ levels have been shown to be in line with that of EPR, enabling the identification of concentrations as low as $1-2 \%$.

This approach thus benefits crystallography measurements of metalloproteins under functional conditions, providing an in situ measure of sample integrity in addition to probing the electronic structure at the metal site(s). The method is general and can be used to study many metalloproteins under the conditions of an XFEL experiment, although we have focused on PS II as an illustrative example in this manuscript. The fast feedback (in a few minutes following the data collection) provided by this approach enables one to assess the in situ measure of sample quality and changes in the chemical states by illumination or chemical reaction or gas activation.

The results presented here have been obtained from measurements at the LCLS, using an XFEL repetition rate of $10 \mathrm{~Hz}$. We have shown that this would require approximately 5 minutes of collection time per state to get a good indication of its chemical state, or 100 minutes per state for final first moment accuracy of $0.005 \mathrm{eV}$. This approach will thus benefit considerably by the construction of the next generation of XFEL featuring very high repetition rates $(>1 \mathrm{kHz})$, such as the European $\mathrm{XFEL}^{41}$ and LCLSII.

\section{Supplementary Material}

Refer to Web version on PubMed Central for supplementary material.

\section{Acknowledgments}

This work was supported by the Director, Office of Science, Office of Basic Energy Sciences (OBES), Division of Chemical Sciences, Geosciences and Biosciences (CSGB) of the US Department of Energy (DOE) under contract DE-AC02-05CH11231 (J.Y. and V.K.Y.) for X-ray methodology and instrumentation, by the US National Institutes of Health (NIH) grants GM110501 (J.Y.) and GM126289 (J.K.) for instrumentation development for XFEL experiments, and GM55302 (V.K.Y.) for PS II biochemistry, structure and mechanism, a Ruth L. Kirschstein National Research Service Award 5 F32 GM116423-02 (F.D.F.), the Human Frontiers Science Project award RGP0063/2013 310 (J.Y., and U.B.), and the Swedish Research Council grant 2017-00356 (T.F.). Use of the Linac Coherent Light Source (LCLS), SLAC National Accelerator Laboratory, is supported by the US DOE, Office of Science, OBES under contract DE-AC02-76SF00515. The SSRL Structural Molecular Biology Program is supported by the DOE OBER, and by the NIH (P41GM103393).

\section{References}

1. Chapman HN, Fromme P, Barty A, White TA, Kirian RA, Aquila A, Hunter MS, Schulz J, DePonte DP, Weierstall U, Doak RB, Maia F, Martin AV, Schlichting I, Lomb L, Coppola N, Shoeman RL, Epp SW, Hartmann R, Rolles D, Rudenko A, Foucar L, Kimmel N, Weidenspointner G, Holl P, 
Liang MN, Barthelmess M, Caleman C, Boutet S, Bogan MJ, Krzywinski J, Bostedt C, Bajt S, Gumprecht L, Rudek B, Erk B, Schmidt C, Homke A, Reich C, Pietschner D, Struder L, Hauser G, Gorke H, Ullrich J, Herrmann S, Schaller G, Schopper F, Soltau H, Kuhnel KU, Messerschmidt M, Bozek JD, Hau-Riege SP, Frank M, Hampton CY, Sierra RG, Starodub D, Williams GJ, Hajdu J, Timneanu N, Seibert MM, Andreasson J, Rocker A, Jonsson O, Svenda M, Stern S, Nass K, Andritschke R, Schroter CD, Krasniqi F, Bott M, Schmidt KE, Wang XY, Grotjohann I, Holton JM, Barends TR M, Neutze R, Marchesini S, Fromme R, Schorb S, Rupp D, Adolph M, Gorkhover T, Andersson I, Hirsemann H, Potdevin G, Graafsma H, Nilsson B, Spence JCH. Femtosecond X-ray protein nanocrystallography. Nature. 2011; 470:73-77. [PubMed: 21293373]

2. Kern J, Alonso-Mori R, Hellmich J, Tran R, Hattne J, Laksmono H, Glockner C, Echols N, Sierra RG, Sellberg J, Lassalle-Kaiser B, Gildea RJ, Glatzel P, Grosse-Kunstleve RW, Latimer MJ, McQueen TA, DiFiore D, Fry AR, Messerschmidt M, Miahnahri A, Schafer DW, Seibert MM, Sokaras D, Weng TC, Zwart PH, White WE, Adams PD, Bogan MJ, Boutet S, Williams GJ, Messinger J, Sauter NK, Zouni A, Bergmann U, Yano J, Yachandra VK. Room temperature femtosecond X-ray diffraction of photosystem II microcrystals. Proc Natl Acad Sci USA. 2012; 109:9721-9726. [PubMed: 22665786]

3. Boutet S, Lomb L, Williams GJ, Barends TRM, Aquila A, Doak RB, Weierstall U, DePonte DP, Steinbrener J, Shoeman RL, Messerschmidt M, Barty A, White TA, Kassemeyer S, Kirian RA, Seibert MM, Montanez PA, Kenney C, Herbst R, Hart P, Pines J, Haller G, Gruner SM, Philipp HT, Tate MW, Hromalik M, Koerner LJ, van Bakel N, Morse J, Ghonsalves W, Arnlund D, Bogan MJ, Caleman C, Fromme R, Hampton CY, Hunter MS, Johansson LC, Katona G, Kupitz C, Liang MN, Martin AV, Nass K, Redecke L, Stellato F, Timneanu N, Wang DJ, Zatsepin NA, Schafer D, Defever J, Neutze R, Fromme P, Spence JCH, Chapman HN, Schlichting I. High-Resolution Protein Structure Determination by Serial Femtosecond Crystallography. Science. 2012; 337:362-364. [PubMed: 22653729]

4. Liu W, Wacker D, Gati C, Han GW, James D, Wang DJ, Nelson G, Weierstall U, Katritch V, Barty A, Zatsepin NA, Li DF, Messerschmidt M, Boutet S, Williams GJ, Koglin JE, Seibert MM, Wang C, Shah STA, Basu S, Fromme R, Kupitz C, Rendek KN, Grotjohann I, Fromme P, Kirian RA, Beyerlein KR, White TA, Chapman HN, Caffrey M, Spence JCH, Stevens RC, Cherezov V. Serial Femtosecond Crystallography of G Protein-Coupled Receptors. Science. 2013; 342:1521-1524. [PubMed: 24357322]

5. Redecke L, Nass K, DePonte DP, White TA, Rehders D, Barty A, Stellato F, Liang MN, Barends TRM, Boutet S, Williams GJ, Messerschmidt M, Seibert MM, Aquila A, Arnlund D, Bajt S, Barth T, Bogan MJ, Caleman C, Chao TC, Doak RB, Fleckenstein H, Frank M, Fromme R, Galli L, Grotjohann I, Hunter MS, Johansson LC, Kassemeyer S, Katona G, Kirian RA, Koopmann R, Kupitz C, Lomb L, Martin AV, Mogk S, Neutze R, Shoeman RL, Steinbrener J, Timneanu N, Wang DJ, Weierstall U, Zatsepin NA, Spence JCH, Fromme P, Schlichting I, Duszenko M, Betzel C, Chapman HN. Natively Inhibited Trypanosoma brucei Cathepsin B Structure Determined by Using an X-ray Laser. Science. 2013; 339:227-230. [PubMed: 23196907]

6. Barends TRM, Foucar L, Botha S, Doak RB, Shoeman RL, Nass K, Koglin JE, Williams GJ, Boutet $\mathrm{S}$, Messerschmidt M, Schlichting I. De novo protein crystal structure determination from X-ray free-electron laser data. Nature. 2014; 505:244-247. [PubMed: 24270807]

7. Tenboer J, Basu S, Zatsepin N, Pande K, Milathianaki D, Frank M, Hunter M, Boutet S, Williams GJ, Koglin JE, Oberthuer D, Heymann M, Kupitz C, Conrad C, Coe J, Roy-Chowdhury S, Weierstall U, James D, Wang DJ, Grant T, Barty A, Yefanov O, Scales J, Gati C, Seuring C, Srajer V, Henning R, Schwander P, Fromme R, Ourmazd A, Moffat K, Van Thor JJ, Spence JCH, Fromme P, Chapman HN, Schmidt M. Time-resolved serial crystallography captures high-resolution intermediates of photoactive yellow protein. Science. 2014; 346:1242-1246. [PubMed: 25477465]

8. Johansson LC, Stauch B, Ishchenko A, Cherezov V. A Bright Future for Serial Femtosecond Crystallography with XFELs. Trends Biochem Sci. 2017; 42:749-762. [PubMed: 28733116]

9. Alonso-Mori R, Kern J, Gildea RJ, Sokaras D, Weng TC, Lassalle-Kaiser B, Tran R, Hattne J, Laksmono H, Hellmich J, Glockner C, Echols N, Sierra RG, Schafer DW, Sellberg J, Kenney C, Herbst R, Pines J, Hart P, Herrmann S, Grosse-Kunstleve RW, Latimer MJ, Fry AR, Messerschmidt MM, Miahnahri A, Seibert MM, Zwart PH, White WE, Adams PD, Bogan MJ, Boutet S, Williams GJ, Zouni A, Messinger J, Glatzel P, Sauter NK, Yachandra VK, Yano J, Bergmann U. Energy- 
dispersive X-ray emission spectroscopy using an X-ray free-electron laser in a shot-by-shot mode. Proc Natl Acad Sci USA. 2012; 109:19103-19107. [PubMed: 23129631]

10. Kern J, Alonso-Mori R, Tran R, Hattne J, Gildea RJ, Echols N, Glockner C, Hellmich J, Laksmono H, Sierra RG, Lassalle-Kaiser B, Koroidov S, Lampe A, Han GY, Gul S, DiFiore D, Milathianaki D, Fry AR, Miahnahri A, Schafer DW, Messerschmidt M, Seibert MM, Koglin JE, Sokaras D, Weng TC, Sellberg J, Latimer MJ, Grosse-Kunstleve RW, Zwart PH, White WE, Glatzel P, Adams PD, Bogan MJ, Williams GJ, Boutet S, Messinger J, Zouni A, Sauter NK, Yachandra VK, Bergmann U, Yano J. Simultaneous Femtosecond X-ray Spectroscopy and Diffraction of Photosystem II at Room Temperature. Science. 2013; 340:491-495. [PubMed: 23413188]

11. Kern J, Tran R, Alonso-Mori R, Koroidov S, Echols N, Hattne J, Ibrahim M, Gul S, Laksmono H, Sierra RG, Gildea RJ, Han G, Hellmich J, Lassalle-Kaiser B, Chatterjee R, Brewster AS, Stan CA, Glockner C, Lampe A, DiFiore D, Milathianaki D, Fry AR, Seibert MM, Koglin JE, Gallo E, Uhlig J, Sokaras D, Weng TC, Zwart PH, Skinner DE, Bogan MJ, Messerschmidt M, Glatzel P, Williams GJ, Boutet S, Adams PD, Zouni A, Messinger J, Sauter NK, Bergmann U, Yano J, Yachandra VK. Taking snapshots of photosynthetic water oxidation using femtosecond X-ray diffraction and spectroscopy. Nature Comm. 2014; 5:4371.

12. Alonso-Mori R, Asa K, Bergmann U, Brewster AS, Chatterjee R, Cooper JK, Frei HM, Fuller FD, Goggins E, Gul S, Fukuzawa H, Iablonskyi D, Ibrahim M, Katayama T, Kroll T, Kumagai Y, McClure BA, Messinger J, Motomura K, Nagaya K, Nishiyama T, Saracini C, Sato Y, Sauter NK, Sokaras D, Takanashi T, Togashi T, Ueda K, Weare WW, Weng TC, Yabashi M, Yachandra VK, Young ID, Zouni A, Kern JF, Yano J. Towards characterization of photo-excited electron transfer and catalysis in natural and artificial systems using XFELs. Faraday Discuss. 2016; 194:621-638. [PubMed: 27711803]

13. Fuller FD, Gul S, Chatterjee R, Burgie ES, Young ID, Lebrette H, Srinivas V, Brewster AS, Michels-Clark T, Clinger JA, Andi B, Ibrahim M, Pastor E, de Lichtenberg C, Hussein R, Pollock CJ, Zhang M, Stan CA, Kroll T, Fransson T, Weninger C, Kubin M, Aller P, Lassalle L, Brauer P, Miller MD, Amin M, Koroidov S, Roessler CG, Allaire M, Sierra RG, Docker PT, Glownia JM, Nelson S, Koglin JE, Zhu DL, Chollet M, Song S, Lemke H, Liang MN, Sokaras D, Alonso-Mori R, Zouni A, Messinger J, Bergmann U, Boal AK, Bollinger JM, Krebs C, Hogbom M, Phillips GN, Vierstra RD, Sauter NK, Orville AM, Kern J, Yachandra VK, Yano J. Drop-on-demand sample delivery for studying biocatalysts in action at X-ray free-electron lasers. Nature Methods. 2017; 14:443-447. [PubMed: 28250468]

14. Bergmann U, Glatzel P. X-ray emission spectroscopy. Photosynth Res. 2009; 102:255-266. [PubMed: 19705296]

15. Glatzel P, Bergmann U. High resolution 1s core hole X-ray spectroscopy in $3 \mathrm{~d}$ transition metal complexes - electronic and structural information. Coord Chem Rev. 2005; 249:65-95.

16. Kowalska JK, Lima FA, Pollock CJ, Rees JA, DeBeer S. A Practical Guide to High-resolution Xray Spectroscopic Measurements and their Applications in Bioinorganic Chemistry. Israel Journal of Chemistry. 2016; 56:803-815.

17. Alonso-Mori R, Sokaras D, Zhu DL, Kroll T, Chollet M, Feng YP, Glownia JM, Kern J, Lemke HT, Nordlund D, Robert A, Sikorski M, Song S, Weng TC, Bergmann U. Photon-in photon-out hard X-ray spectroscopy at the Linac Coherent Light Source. J Synchrotron Radiat. 2015; 22:612620. [PubMed: 25931076]

18. Young L, Kanter EP, Krassig B, Li Y, March AM, Pratt ST, Santra R, Southworth SH, Rohringer N, DiMauro LF, Doumy G, Roedig CA, Berrah N, Fang L, Hoener M, Bucksbaum PH, Cryan JP, Ghimire S, Glownia JM, Reis DA, Bozek JD, Bostedt C, Messerschmidt M. Femtosecond electronic response of atoms to ultra-intense X-rays. Nature. 2010; 466:56-61. [PubMed: 20596013]

19. Tamasaku K, Shigemasa E, Inubushi Y, Katayama T, Sawada K, Yumoto H, Ohashi H, Mimura H, Yabashi M, Yamauchi K, Ishikawa T. X-ray two-photon absorption competing against single and sequential multiphoton processes. Nature Photonics. 2014; 8:313-316.

20. Sierra RG, Laksmono H, Kern J, Tran R, Hattne J, Alonso-Mori R, Lassalle-Kaiser B, Glockner C, Hellmich J, Schafer DW, Echols N, Gildea RJ, Grosse-Kunstleve RW, Sellberg J, McQueen TA, Fry AR, Messerschmidt MM, Miahnahri A, Seibert MM, Hampton CY, Starodub D, Loh ND, Sokaras D, Weng TC, Zwart PH, Glatzel P, Milathianaki D, White WE, Adams PD, Williams GJ, 
Boutet S, Zouni A, Messinger J, Sauter NK, Bergmann U, Yano J, Yachandra VK, Bogan MJ. Nanoflow electrospinning serial femtosecond crystallography. Acta Crystallogr D- Struct Biol. 2012; 68:1584-1587.

21. Sierra RG, Gati C, Laksmono H, Dao EH, Gul S, Fuller F, Kern J, Chatterjee R, Ibrahim M, Brewster AS, Young ID, Michels-Clark T, Aquila A, Liang M, Hunter MS, Koglin JE, Boutet S, Junco EA, Hayes B, Bogan MJ, Hampton CY, Puglisi EV, Sauter NK, Stan CA, Zouni A, Yano J, Yachandra VK, Soltis SM, Puglisi JD, DeMirci H. Concentric-flow electrokinetic injector enables serial crystallography of ribosome and photosystem II. Nat Methods. 2016; 13:59-62. [PubMed: 26619013]

22. Yano J, Yachandra V. Mn4Ca Cluster in Photosynthesis: Where and How Water is Oxidized to Dioxygen. Chem Rev. 2014; 114:4175-4205. [PubMed: 24684576]

23. Cox N, Messinger J. Reflections on substrate water and dioxygen formation. Biochim Biophys Acta-Bioenerg. 2013; 1827:1020-1030.

24. Boutet S, Cohen A, Wakatsuki S. The New Macromolecular Femtosecond Crystallography (MFX) Instrument at LCLS. Synchrotron Radiat News. 2016; 29:23-28. [PubMed: 28736484]

25. Emma P, Akre R, Arthur J, Bionta R, Bostedt C, Bozek J, Brachmann A, Bucksbaum P, Coffee R, Decker FJ, Ding Y, Dowell D, Edstrom S, Fisher A, Frisch J, Gilevich S, Hastings J, Hays G, Hering P, Huang Z, Iverson R, Loos H, Messerschmidt M, Miahnahri A, Moeller S, Nuhn HD, Pile G, Ratner D, Rzepiela J, Schultz D, Smith T, Stefan P, Tompkins H, Turner J, Welch J, White W, $\mathrm{Wu}$ J, Yocky G, Galayda J. First lasing and operation of an angstrom-wavelength free-electron laser. Nature Photonics. 2010; 4:641-647.

26. Young ID, Ibrahim M, Chatterjee R, Gul S, Fuller FD, Koroidov S, Brewster AS, Tran R, AlonsoMori R, Kroll T, Michels-Clark T, Laksmono H, Sierra RG, Stan CA, Hussein R, Zhang M, Douthit L, Kubin M, de Lichtenberg C, Pham LV, Nilsson H, Cheah MH, Shevela D, Saracini C, Bean MA, Seuffert I, Sokaras D, Weng TC, Pastor E, Weninger C, Fransson T, Lassalle L, Brauer P, Aller P, Docker PT, Andi B, Orville AM, Glownia JM, Nelson S, Sikorski M, Zhu DL, Hunter MS, Lane TJ, Aquila A, Koglin JE, Robinson J, Liang MN, Boutet S, Lyubimov AY, Uervirojnangkoorn M, Moriarty NW, Liebschner D, Afonine PV, Waterman DG, Evans G, Wernet P, Dobbek H, Weis WI, Brunger AT, Zwart PH, Adams PD, Zouni A, Messinger J, Bergmann U, Sauter NK, Kern J, Yachandra VK, Yano J. Structure of photosystem II and substrate binding at room temperature. Nature. 2016; 540:453-457. [PubMed: 27871088]

27. Alonso-Mori R, Kern J, Sokaras D, Weng TC, Nordlund D, Tran R, Montanez P, Delor J, Yachandra VK, Yano J, Bergmann U. A multi-crystal wavelength dispersive x-ray spectrometer. Rev Sci Instrum. 2012; 83:073114. [PubMed: 22852678]

28. Blaj G, Caragiulo P, Carini G, Carron S, Dragone A, Freytag D, Haller G, Hart P, Hasi J, Herbst R, Herrmann S, Kenney C, Markovic B, Nishimura K, Osier S, Pines J, Reese B, Segal J, Tomada A, Weaver M. X-ray detectors at the Linac Coherent Light Source. J Synchrotron Radiat. 2015; 22:577-583. [PubMed: 25931071]

29. Baumbaugh A, Carini G, Deptuch G, Grybos P, Hoff J, Maj P, Siddons P, Szczygiel R, Trimpl M, Yarema R. Analysis of full charge reconstruction algorithms for X-ray pixelated detectors. IEEE Nuclear Science Symposium Conference Record. 2011:660-667.

30. Messinger J, Robblee JH, Bergmann U, Fernandez C, Glatzel P, Visser H, Cinco RM, McFarlane KL, Bellacchio E, Pizarro SA, Cramer SP, Sauer K, Klein MP, Yachandra VK. Absence of Mncentered oxidation in the S-2 -> S-3 Transition: Implications for the mechanism of photosynthetic water oxidation. J Am Chem Soc. 2001; 123:7804-7820. [PubMed: 11493054]

31. Jensen SC, Davis KM, Sullivan B, Hartzler DA, Seidler GT, Casa DM, Kasman E, Colmer HE, Massie AA, Jackson TA, Pushkar Y. X-ray Emission Spectroscopy of Biomimetic Mn Coordination Complexes. J Phys Chem Lett. 2017; 8:2584-2589. [PubMed: 28524662]

32. Davis KM, Palenik MC, Yan LF, Smith PF, Seidler GT, Dismukes GC, Pushkar YN. X-ray Emission Spectroscopy of Mn Coordination Complexes Toward Interpreting the Electronic Structure of the Oxygen-Evolving Complex of Photosystem II. J Phys Chem C. 2016; 120:33263333.

33. Pizarro SA, Glatzel P, Visser H, Robblee JH, Christou G, Bergmann U, Yachandra VK. Mn oxidation states in tri- and tetra-nuclear Mn compounds structurally relevant to photosystem II: 
MnK-edge X-ray absorption and K beta X-ray emission spectroscopy studies. Phys Chem Chem Phys. 2004; 6:4864-4870. [PubMed: 25383041]

34. Visser H, Anxolabehere-Mallart E, Bergmann U, Glatzel P, Robblee JH, Cramer SP, Girerd JJ, Sauer K, Klein MP, Yachandra VK. MnK-edge XANES and K beta XES studies of two Mn-oxo binuclear complexes: Investigation of three different oxidation states relevant to the oxygenevolving complex of photosystem II. J Am Chem Soc. 2001; 123:7031-7039. [PubMed: 11459481]

35. Zaharieva I, Dau H, Haumann M. Sequential and Coupled Proton and Electron Transfer Events in the S-2 -> S-3 Transition of Photosynthetic Water Oxidation Revealed by Time-Resolved X-ray Absorption Spectroscopy. Biochemistry. 2016; 55:6996-7004. [PubMed: 27992997]

36. Kok B, Forbush B, McGloin M. Cooperation of Charges in Photosynthetic O2 Evolution .1. A Linear 4Step Mechanism. Photochem Photobiol. 1970; 11:457-475. [PubMed: 5456273]

37. Vanko G, Neisius T, Molnar G, Renz F, Karpati S, Shukla A, de Groot FMF. Probing the 3d spin momentum with X-ray emission spectroscopy: The case of molecular-spin transitions. J Phys Chem B. 2006; 110:11647-11653. [PubMed: 16800459]

38. Gul S, Ng JWD, Alonso-Mori R, Kern J, Sokaras D, Anzenberg E, Lassalle-Kaiser B, Gorlin Y, Weng TC, Zwart PH, Zhang JZ, Bergmann U, Yachandra VK, Jaramillo TF, Yano J. Simultaneous detection of electronic structure changes from two elements of a bifunctional catalyst using wavelength-dispersive X-ray emission spectroscopy and in situ electrochemistry. Phys Chem Chem Phys. 2015; 17:8901-8912. [PubMed: 25747045]

39. Glatzel P, Bergmann U, Yano J, Visser H, Robblee JH, Gu WW, de Groot FMF, Christou G, Pecoraro VL, Cramer SP, Yachandra VK. The electronic structure of Mn in oxides, coordination complexes, and the oxygen-evolving complex of photosystem II studied by resonant inelastic Xray scattering. J Am Chem Soc. 2004; 126:9946-9959. [PubMed: 15303869]

40. Glatzel P, Schroeder H, Pushkar Y, Boron T, Mukherjee S, Christou G, Pecoraro VL, Messinger J, Yachandra VK, Bergmann U, Yano J. Electronic Structural Changes of Mn in the OxygenEvolving Complex of Photosystem II during the Catalytic Cycle. Inorg Chem. 2013; 52:56425644. [PubMed: 23647530]

41. Tschentscher T, Bressler C, Grunert J, Madsen A, Mancuso AP, Meyer M, Scherz A, Sinn H, Zastrau U. Photon Beam Transport and Scientific Instruments at the European XFEL. Appl Sci. 2017; 7:592. 

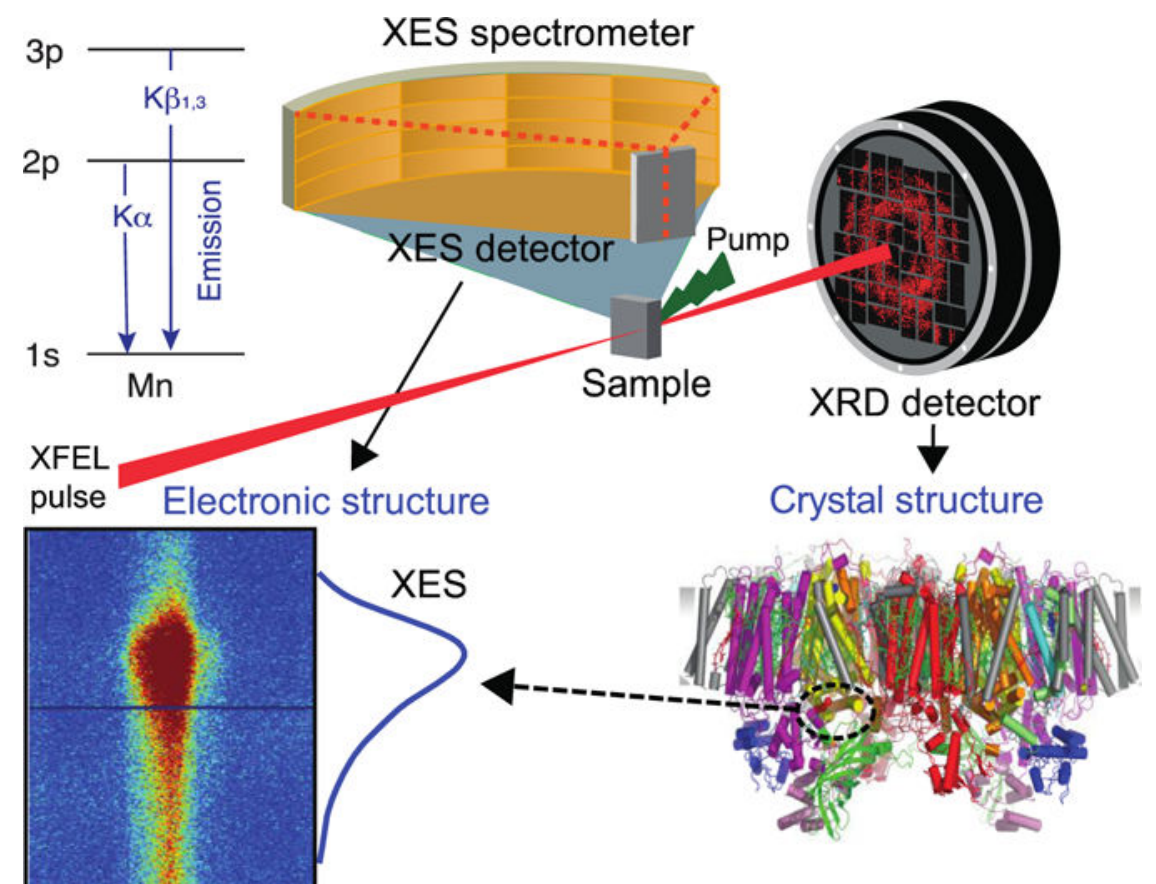

Fig. 1.

Schematic for simultaneous XRD and XES measurements using either a jet injector ${ }^{20}$ or the Drop-on-Tape (DOT) ${ }^{13}$ method giving both diffraction images and XES spectrum. This setup utilizes a von Hamos spectrometer for XES data collection, which enables the detection of the entire $\mathrm{K} \beta_{1,3}$ spectra in an energy dispersive mode on a position sensitive 2D detector on a shot-by-shot basis. Upper left: energy diagram of $\mathrm{Ka}$ and $\mathrm{K} \beta_{1,3}$ transitions. 

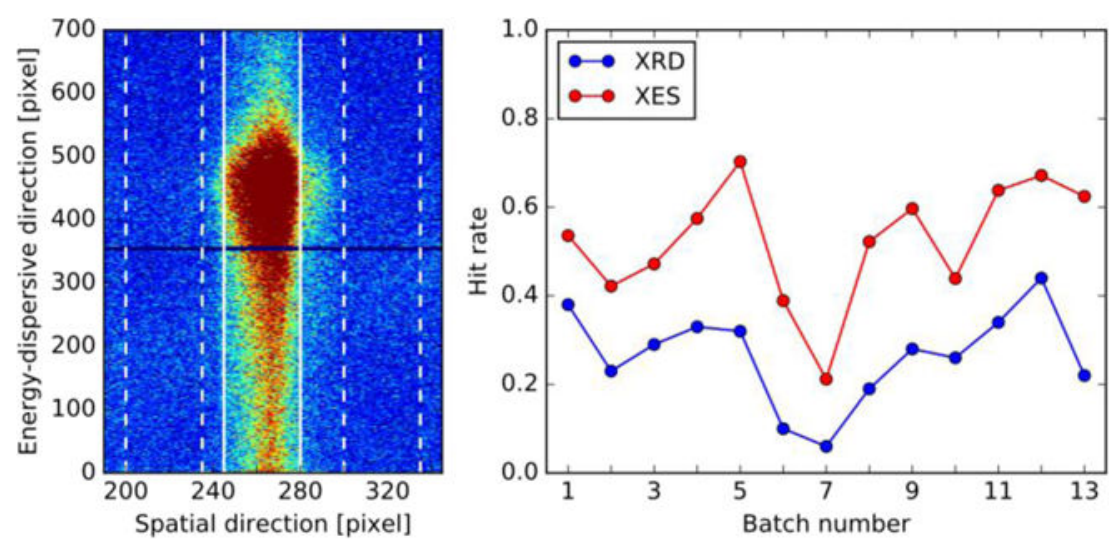

Fig. 2.

(left) Total detector image of the dark state (0-Flash, $0 \mathrm{~F})$ collected during experiment 1. Vertical lines indicating ROI, and vertical dashed lines indicating slices for background subtraction and comparison region for hit finder. The image is the sum of all XES images counted as hits (totally 22,606, with 177,639 detected emission photons). (right) Average hit/indexing rates of different sample batches from experiment 1, estimated using the spectroscopic hit finder (red) and indexing rates from crystallography (blue). 

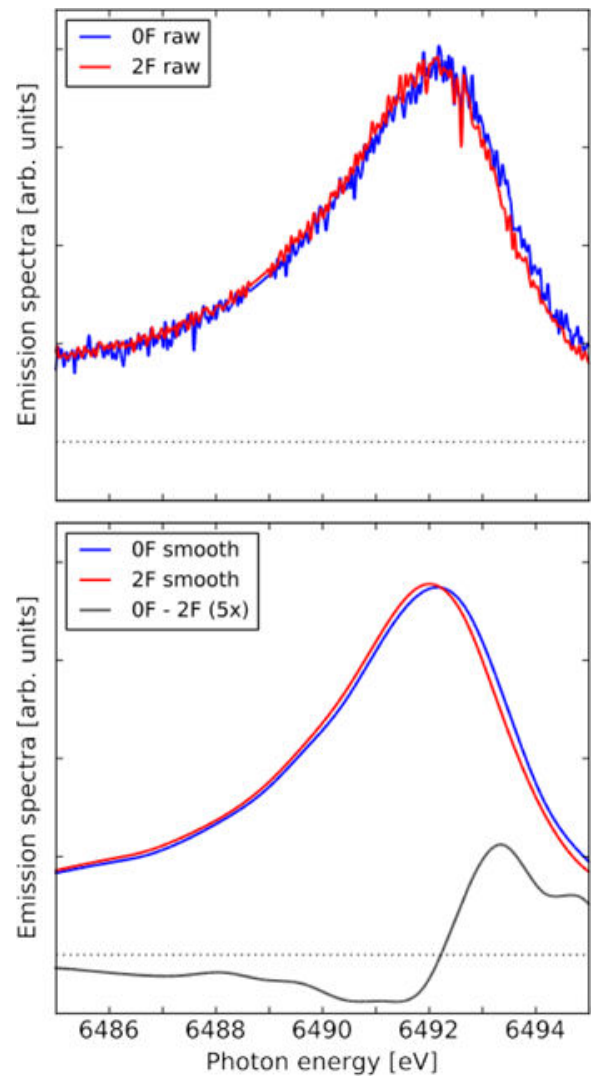

Fig. 3 .

$\mathrm{K} \beta_{1,3}$ emission spectra of the $0 \mathrm{~F}$ and $2 \mathrm{~F}$ flash states from experiment 1 , as well as the $0 \mathrm{~F}-2 \mathrm{~F}$ difference spectrum (enlarged by a factor of 5). The spectra were area normalized inside the adopted energy interval. The smoothed spectra have been constructed by first binning the raw spectra to $0.75 \mathrm{eV}$ resolution and then using a cubic spline to construct smoothed spectra of $0.01 \mathrm{eV}$ resolution. The $\mathrm{OF}$ data contains 22,606 shots and totally 177,639 emission photons, while $2 \mathrm{~F}$ contains 67,219 shots and 590,156 emission photons. 

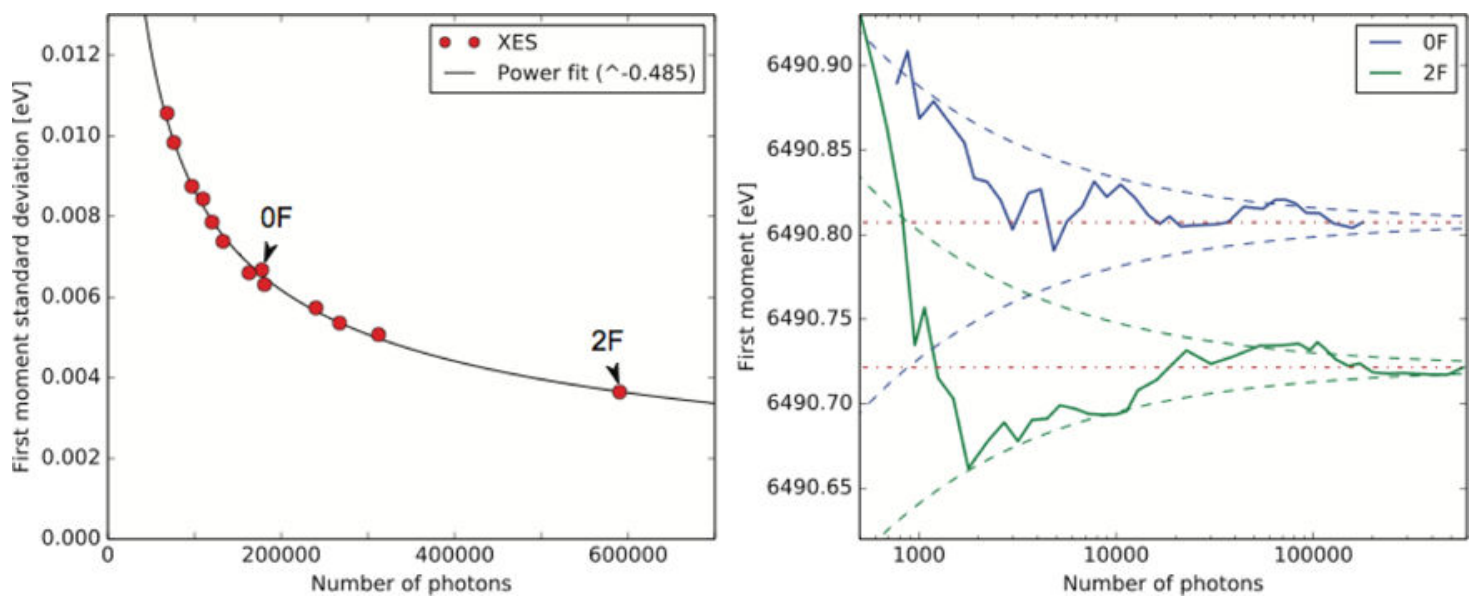

Fig. 4.

(left) First moment variance of all measured flash states with respect to total number of detected $\mathrm{K} \beta_{1,3}$ emission photons, also indicating the $0 \mathrm{~F}$ and $2 \mathrm{~F}$ data used in Fig. 3. Included is also a power fit, yielding close to a square-root dependence and a $\mathrm{R}^{2}$ value of 0.996 .

(right) $0 \mathrm{~F}$ and $2 \mathrm{~F}$ first moments as a function of number of photons, illustrated for data collected during experiment 1 . Indicated is also the estimated first moment variance (dashed lines, in blue for $0 \mathrm{~F}$ and green $2 \mathrm{~F}$ ) using the power fit with parameters from the left panel, as centered around final first moments (dotted-dashed lines in red). 


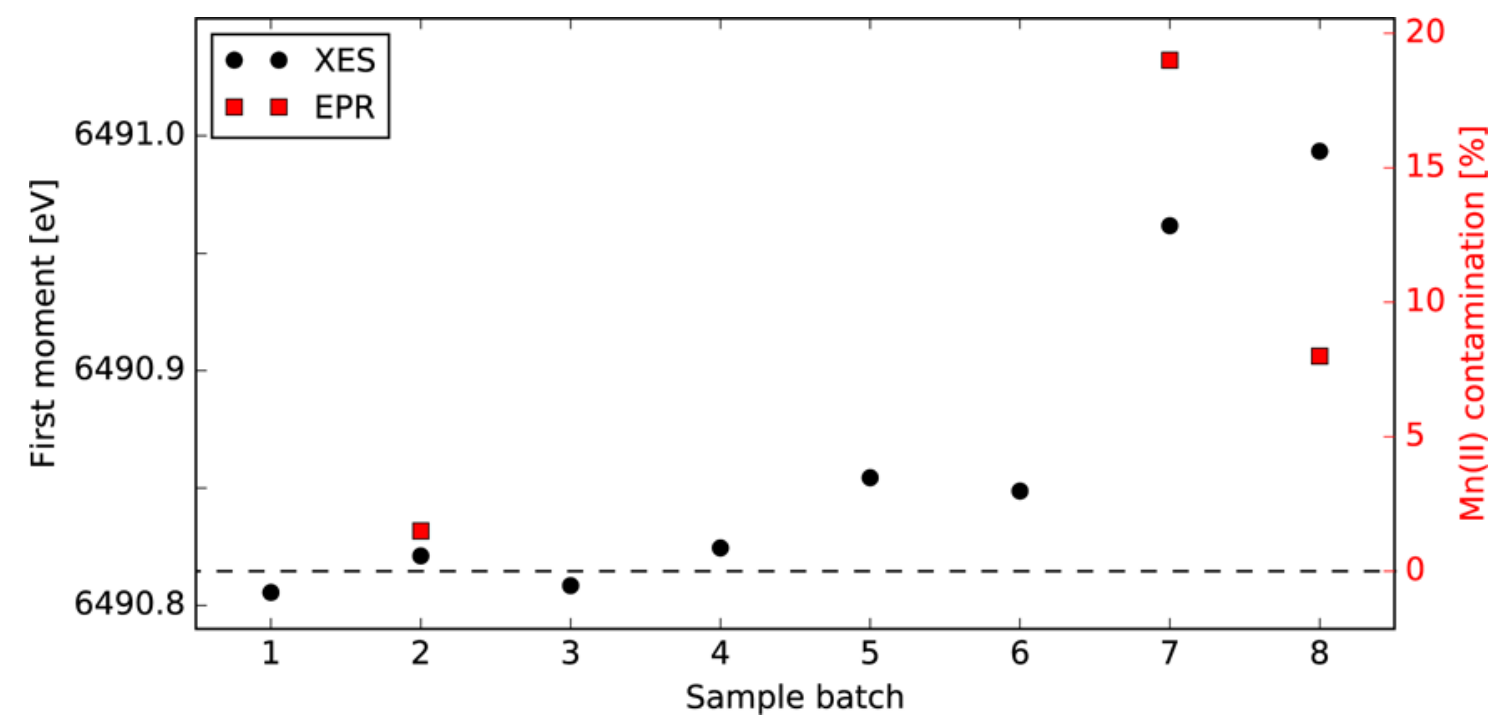

Fig. 5.

$0 \mathrm{~F}_{\text {est }}$ first moments and $\mathrm{Mn}$ (II) levels of different sample batches from experiment 2. Horizontal dashed line is the $0 \mathrm{~F}$ first moment, which has negligible $\mathrm{Mn}(\mathrm{II})$, and higher percentages are constructed by considering the $\mathrm{Mn}$ (II) first moment from $\mathrm{MnCl}_{2}$ reference measurements. XES estimates include standard deviation for photon count. 


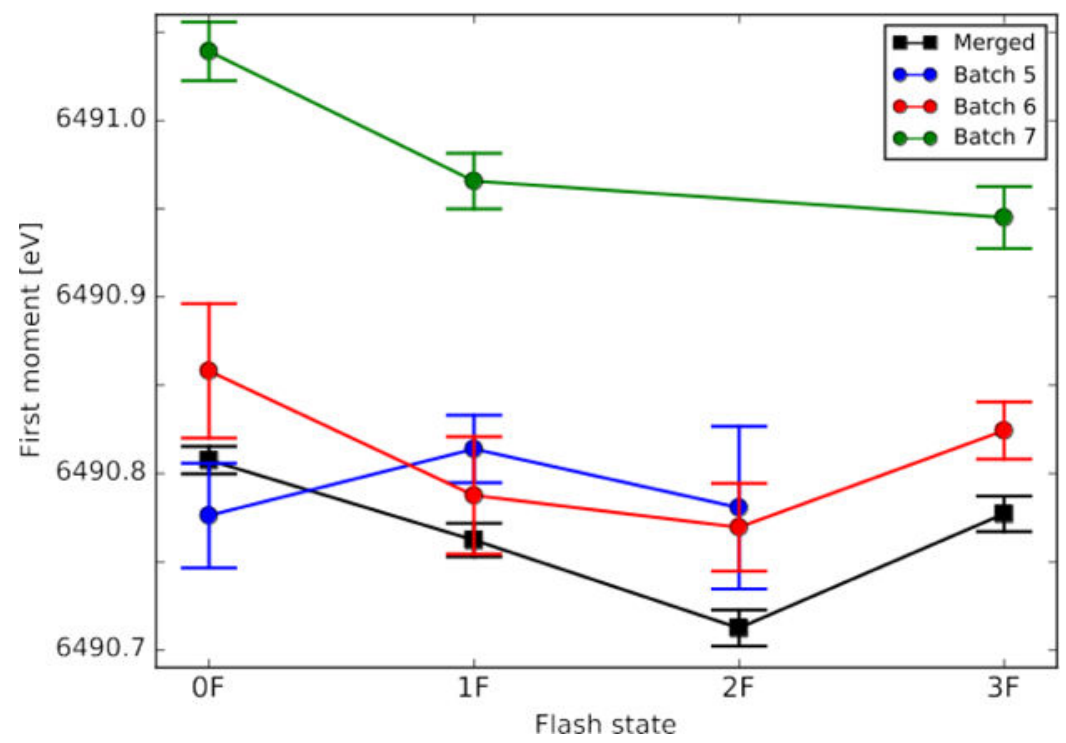

Fig. 6.

First moment progressions of three anomalous sample batches from experiment 2, as compared to the averages of the good batches. Standard deviations calculated by random sampling of data sets (200 iterations). 